\title{
Ethic Cultural Construction Based on the Social Stability
}

\author{
Weiping Lei \\ Wuhan university of Technology \\ E-mail: leiwp@tom.com
}

\author{
Key Words: Social Stability; Ethic Culture; Tactics
}

\begin{abstract}
Social stability is the basis for the development of a society and it is the prerequisite for a country to achieve prosperity. And a nation can achieve stability only by strengthening the ethical and cultural construction. This paper mainly discusses the relationship between human society and the nature; it also studies how ethic culture regulates the relationship. In the end, it concludes that in order to achieve social stability through ethic culture construction, the government should put emphasis on acting a leading role in all kinds of aspect. Such as strengthening the moral education in public, absorbing the outstanding part of traditional ethic culture and internalizing the moral ideal into the spirit of practice ect.
\end{abstract}

\section{Introduction}

"Social stability is a necessary condition for human to maintain a normal life; it is an important foundation for the progress and development of the society and it account for a fundamental premise of nations' prosperous." [1] Ethic culture is kind of social culture, and it is paralleled to legal culture, just culture and business culture with a side-by-side relationship. What's more, ethic culture permeates with a deep human wisdom; it expresses the spirit of social morality and ethical wisdom, and it embodies the rational thinking and values of our nation. All in all, ethic culture plays an important role in maintaining social stability.

\section{The role of ethical culture in social stability}

A. Ethical culture regulate the relationship between people in keeping social stability.

In the development and progress period of mankind, the interpersonal relationships exist at anytime and in everywhere. People deal with the various relationships to achieve their own growth and improvement and to advance the development and progress of society. If people cannot handle well by the relationship in social life, then society also can certainly not be stable. The interpersonal relationship is a relatively complex social phenomenon built up in the social life and it is an interest relation essentially. If the relationships between people in social life lack for understanding and trust, lack for communication and tolerance, then society will be full of indifference conflict, even hatred and violence. And the society must be in a very unstable state. Ethical culture is an important force to make the public more united and fraternal. In regulating relationships, Ethical Culture runs by using the moral standards and ethical norms to regulate the relations between people. "Social stability requires the stability of the human relations." [2] If there is no role of ethical culture plays in regulating human relationships, the society and the interpersonal relationships would not be stable. So in order to achieve social stability, it is necessary to give full use of the function of the Ethical Culture. Use it to promote people's moral qualities and personal accomplishment. Through the outstanding moral ideals and principle, we can regulate the relationship between people and form a mutual respectful, trustful enthusiastic and friendly relationship. Not only does it conducive to their own development, but also conducive to social development and stability.

B. Ethical culture modulates the connection between man and nature in keeping social stability.

Human was born in nature and depended on the nature, the relationship between man and nature is inseparable. We should protect the nature and learn a harmonize way to develop with nature. The 
excessive human destruction of the natural environment or not to adjust the relationship between man and nature can lead to an upheaval society. Along with the rapid development of society, the over-exploitation of natural resources leading to the impact on the natural environment and the extent of damage is worsening. It has affected survival of humanity and even deepened the conflict between man and nature. Faced with the deepening of the contradictions of human beings and nature, mankind must re-examine their own behavior, pay attention to the protection of the environment and learn to respect nature. What's more, we should learn using ethical cultural to regulate the human behavior, promote man and nature to live in harmony with nature, to live in common prosperity and live in common development. Otherwise the humans may have no peace, be caught in a crisis of survival, and the society will not be stable. "In the course of history, it can be seen that when the balance between ecological natures or the balance between human and nature is being broken, disaster in human society will come one after another. " ${ }^{[3]}$ Hence, we should be kind to the nature, respect the nature and make sure the relationship with nature being in a good condition. And then achieve social stability. Also because the nature is the basis for human beings and a bad condition of nature would threaten the mankind. Then we can make use of criterion in ethic culture. It can constrain human in the behavior when deal with nature and adjust the relationship with nature. It can lead to a sustainable development. And it lead to a more sable society.

\section{Ethical culture adjusts the nexus between man and nature in keeping social stability.}

Not only should one handle the relationship with nature, but also the relationship with society. And a society without mankind is not a real society. Marx pointed in the "Feuerbach" that Abstraction inherent in human nature is not a single person. In its reality, it is the sum of all social relations." ${ }^{[4]}$ People are social beings and society is the human society. The nature of the property lies in the social being and society is an organism. When the community uncoordinated as a whole and the relationship uncoordinated between man and society, it will have social problems. The dialectical relationship between human and society is interdependence, mutual restraint and mutual promotion. Only dialectical approach and deal with the relationship between the individual and society can lead to a stable society. In order to achieve social stability, we must correctly handle the relationship of man and society. And it is the only way to resolve the conflicts and contradictions of human and society. It makes all efforts conducive to social development factors to be burst and social order in stability manner. People are social beings as the main character in social activities. So one should control himself, re-invent himself and understand himself in a proper way. In order to achieve social stability, one should learn to handle the relationship with society rely on the moral strength in order to serve the community and others. In order to make use of the moral force, we should rely on ethic culture. As the ethic culture contains the selfless, willing to sacrifice, distinguish between right and wrong, the courage to explore, unity, cooperation and other moral ideals or moral beliefs. It is a kind of powerful spiritual force, which regulates the relationship between man and society and promotes the social stability.

\section{Strategy in ethical culture building based on social stability}

\section{A. Giving full play to the leading role of government and it is the basis of the ethical and cultural construction.}

In the construction of ethical cultural, we should give full play to the role of government. Government should use correct ethical orientation to guide people what to do, what not to do and what is right, what is wrong. Give full play to the role of the government is the basis in ethical cultural construction. A proper ethical orientation is the one that governments at all levels chose in a variety of ethical values which is in line with of social development and in line with of needs of the time value guidance. As for now in the construction of ethic culture, government should focus on the following aspects: first of all, to establish a scientific and rational system for ethic norm. Government is a public manager who represents safeguards and realizes the public interest. It tells the kinds of responsibility should people bear, the moral rights people should enjoy and the kinds of 
obligation people should accomplish. All of this can be regulated or constraint through government's ethic system. Secondary, government should guide and supervise the ethical behavior of the public. In the one hand, the government is a organizer or coordinator for the interests of public. So it can take administrative, legal, economic and other means to guide the behavior in public. On the other hand, government should fully mobilize and relies on a variety of social forces to supervise the ethical behavior in the community. Especially to make full use of varieties of public opinions, the media and various industry associations and other social organizations. Thirdly, governments at all levels should urge relevant organizations to establish ethical rating agencies. The relevant government should take the leading role in the establishment of an ethic rating agencies. After a scientific basis, principles and methods for evaluation being established, we can compare and assess ethic condition in various regions and types of organizations. And government can take the ethic assessment as an important part for the evaluation in different regions and organizations.

\section{B. Strengthening the ethical education of the people and it is the key to the construction of the ethical culture.}

Ethics is generated and developed accompanied by the emergence of human. So it has been inherited and perfected by generations after generations. It shows a rich content and has a very role in carrying forward the social development and civilization. According to a certain ethic standards, we plan organized activities to influence to the public, which aims to raise the public's ethic consciousness. The implement of social stability depends largely on the ethic quality of the members of society. And the ethic level of quality directly affects the public's ability to correctly handle the relationship between people, people and society, man and nature. Hence, the main purpose of ethic culture constructing is to deal the relationships between man, nature and society. What ethical education trying to do is to enhance the quality of public ethics. And from a view of social, the minimum requirement of the ethical education is to urge the public to be a man that is useful for our society. What's more, it promotes the social morality, urge the public not to jeopardize the social order or undermine social stability. By the public under ethical education, ethical education raises their moral realm and their own quality. And it promotes physical or mental health; it opens a way to the full and free development. Educational public is the subject of ethical education and the ethic is the most fundamental for the development of human beings. Ethical education is a process that the public learn to regulate himself, it is a process that public learn to adjust the relationships of himself, society and nature. So under a condition of strengthening the ethical education, raising the ideological consciousness and moral level of the public through excellent ethic ideas is the only way to conduct the public. It is the only way to benefit the public and consistent with the requirements of social development and it benefits the ethical construction. In order to improve the level of social ethics through educational campaigns or a better work of press supervision, we need to grasp the characteristics of ethical education, strengthen the relevance and effectiveness of the ethical education. Then the ethics education truly become an important force for social stability and truly beneficial to the ethics educational construction.

\section{Learning from and absorbing the tradition of excellence ethical culture and it is the momentum of ethical culture construction.}

Nowadays, China's cultural, social, economical, political and ecological civilization and development are inseparable from the profound cultural background. The main reasons of our continuous ethical culture are the inheritance and the development of our traditional ethics. Traditional Chinese ethical culture such as people-oriented, people with love, morals and sacrifice for justice still play an important role in today's ethical culture construction. And drawing on the traditional excellent ethical culture is the momentum for ethical culture building. In the construction of ethical culture base on social stability, we can commence on our traditional quality. And the traditional ethics such as sacrifice justice tell people to establish a correct world outlook, values and outlook on life. In front of faith and justice, there are acts that are faithful and justifiable over personal gain. So in the construction of ethical culture base on social stability, traditional ethical culture of honesty and trustworthiness, kindness, helpfulness, sacrifice justice, courageous is definitely very important. And we need to draw on the tradition of outstanding ethical culture to 
change the current social reality mercenary and other unhealthy tendencies. Then advocate that the need to establish a correct concept of justice and personal gain.

\section{Internalizing the spirit of moral ideal into practice among people and it is the foundation for ethical cultural construction.}

The moral ideal is a strong power to lead the public to resist the fake, the wicked and the ugly, to adhere to the good and the beautiful, to perfect themselves, to serve the community, to create a good social climate. The moral ideal is not only a process of thinking and understanding, but also a process of conscious practice. Similarly, building up the ethical cultural is not only a process of cognition, is even more a process of practice. Ethical theory tells us: "moral, as the spirit of practice, is not only the value, but also the action to realize the value, and it is an activity with purpose." ${ }^{[5]}$ The action of practical value is the practical spirit. Now China is in the period of social transformation, with the economic globalization strengthened constantly and more frequent exchanges happened among different civilizations, all kinds of ideas collide with each other, various ideologies and cultures interact with each other, the difference, independence, selectivity and variability in people's ideological activities constantly enhance, the values of the public is also showing a trend of diversity, and a variety of social thought is more active than ever, which is keeping on emerging. The key to form a good moral realm in the whole society and strengthen the ethical culture construction lies in internalizing the ideal moral as the spirit of practice. Only by internalizing the ideal moral as the spirit of practice, can we effectively stimulate the ethical foundation in ethical culture such as willing to sacrifice, love, generous, selfless, harmony, courage to explore, discernment affair, unity and cooperation, mutual help, personal loyalty, etc, and further promote the ethical cultural construction, Let ethical culture play its proper value. To internalize the ideal moral as the spirit of practice, for one hand, people are asked to start from the front, ourselves, and the trivial, for another hand, in the usual study, work, life, people must adhere to the principle of matching words with deeds and integrating Knowledge with Behavior, and tangibly embody the ethical foundation.

\section{Conclusion}

Ethical culture is traditional ethics virtues of people in the long-term social life, it is the sum of the relationship between the spirit and ethics and it is the manifestation of the relationship between the interests of the community and social interactions essentially. So we need to strengthen the ethical and cultural construction as the ethics has an important role to achieve social stability.

\section{Reference:}

[1] Lei Weiping, Cultural Strategy of Social Stability [J], Academic Exchange, 2012(6),135.

[2] Lei Weiping, On the Social Stability Function of Culture [J], Journal of Southwest Agricultural University (Social Science Edition),2012(8),60.

[3] Song Changchun, Harmonious society and human's all-round development[J], Jiangsu Higher Education, 2006 (1) , 111.

[4] Karl Marks, Friedrich Von Engels; Marx and Engels, Selected Works (Volume1) [M], People's

Publishing House, Beijing, 1995, 60.

[5] Luo Guojie, Ethics [M]. People's Publishing House, Beijing, 2007, 54. 